\title{
A social-economic-engineering combined framework for decision making in water resources planning
}

\author{
E. S. Chung ${ }^{1}$ and K. S. Lee ${ }^{2}$ \\ ${ }^{1}$ Engineering Research Institute, Seoul National University, 36-203. San 56-1, Sillim-dong, Gwansk-gu, Seoul, 151-742, \\ Republic of Korea \\ ${ }^{2}$ Department of Civil and Environmental Engineering, Seoul National University, 38-415, San 56-1, Sillim-dong, Gwanak-gu, \\ Seoul, 151-742, Republic of Korea
}

Received: 18 August 2008 - Published in Hydrol. Earth Syst. Sci. Discuss.: 16 October 2008

Revised: 17 April 2009 - Accepted: 24 April 2009 - Published: 27 May 2009

\begin{abstract}
This study develops a social-economicengineering combined framework for decision making in water resources planning. This framework consists of four parts which are to spatially identify the grades on hydrological vulnerability (potential streamflow depletion and potential water quality deterioration), to evaluate the monetary values of improvements on hydrological vulnerability grades using the choice experiment method, to derive an alternative evaluation index (AEI) to quantify the effectiveness of all alternatives, and to combine the derived willingness-topays (WTPs) with the AEI and do the cost-benefit analysis of feasible alternatives. This framework includes the stakeholder participation in order to quantify the preferences with regard to management objectives (water quantity and quality) and WTPs of alternatives. Finally, the economic values of each alternative can be estimated by this study which combines the WTPs for improvements on hydrologic vulnerability grades with the AEI. The proposed procedure is applied in the Anyangcheon watershed which has been highly urbanized for past thirty years. As a result, WTPs are $\$ 0.24 \sim \$ 10.08 /$ month-household for water quantity and $\$ 0.80 \sim \$ 8.60 /$ month-household for water quality and residents of the five regions among six have higher WTPs for water quality improvement. Finally, since three of ten alternatives have $\mathrm{BC}>0$, they can be proposed to the decision makers. This systematic screening procedure will provide decision makers with the flexibility to obtain stakeholders' consensus for water resources planning.
\end{abstract}

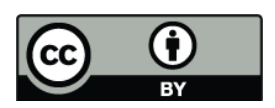

Correspondence to: E. S. Chung (cool77@snu.ac.kr)

\section{Introduction}

Policies directing or guiding every decision by many individuals are usually not developed by the people affected by these policies. Usual studies for input to environmental decision making, including computerized models, often don't involve the relevant stakeholders. At best, experts consult individual stakeholders for their studies or models. At worst, the studies are most often performed by experts, after which decision makers weigh the outcomes against society's needs (or political agendas). Consequently, the broader stakeholders don't understand or don't agree with the underlying assumptions, do not agree with the structure of the models, or refuse to accept the outcomes because they feel left out of the decision making process. For these reasons, conflicts are likely to arise during the implementation phase (Cupps, 1977; Rosener, 1982; Thomas, 1990; van den Belt, 2004; Christofides et al., 2005; Raadgever et al., 2008).

The Water Framework Directive has been brought about in the regulation and management of water resources. Major changes include: 1) a requirement for the preparation of integrated river basin/watershed management plans, with remittent extending over point and non-point pollution, water abstraction and land use; 2) the introduction of a basin-wide target of 'good ecological status' for all surface water and groundwater; 3) the introduction of full social cost pricing for water use; and 4) the incorporation of estimates of economic cost and benefits in catchment management plans. Therefore, Hanley et al. (2006) derived the values people place on improvements in three ecological indicators and thus on the non-market economic benefits of moves towards good ecological status. Therefore, this study estimates the value of

Published by Copernicus Publications on behalf of the European Geosciences Union. 


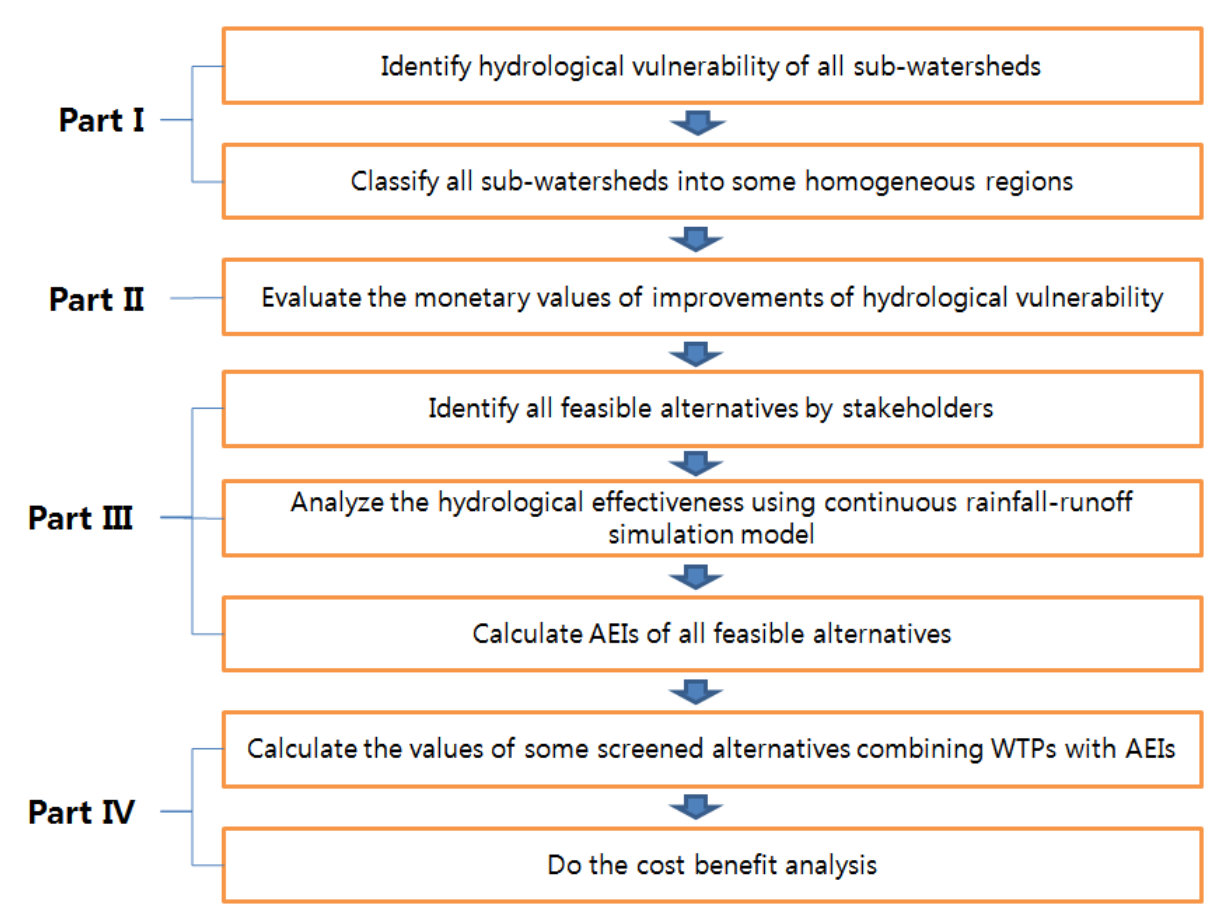

Fig. 1. Procedure of the social-economic-engineering combined framework.

improvements in environmental indicators using the choice experiment (CE) method, such as Hanley et al. (2006). Furthermore, we evaluate the economic values of alternatives combining the value of improvements in environmental indicators and alternative evaluation index (AEI). This method is applied to the Anyangcheon watershed which has been highly urbanized for past thirty years in Korea.

There are various methods to estimate the economic value of the environment. Valuing willingness to pay (WTP) is useful for reliability planning. If a reliability enhancement project's cost is less than consumers' WTP, the project is economically attractive (Abrahams et al., 2000). Conversely, in highly reliable systems consumers might willingly accept a greater frequency of shortages in exchange for reduced water bills (Howe and Smith, 1994). The contingent valuation method (CVM) is one of the most frequently used methods among them. An individual's WTP can be elicited using CVM, but it gives no information on the relative importance among different types of environmental issues. Choice experiments (CEs) potentially outperform CVM with regard to estimating an individual's marginal WTP (MWTP) for each environmental impact, which can then be converted to the relative importance of the different types of environmental issues. Thus CEs have the ability to yield more data than CVM (Nakatani et al., 2007).

There are some drawbacks in CEs. The scope insensitivity (embedding effect) which has long been discussed is said to be the most difficult problem in CVM studies and is also a serious problem in CE studies. According to Harrision (1992), the embedding effect is defined as follows: it occurs when the WTP for one good is found to be insignificantly different from the WTP for a more inclusive good (Nakatani et al., 2007). As Schulze et al. (1998) described, scope insensitivity has generated extreme views that range from the suggestion that embedding effects are so severe that they make CVM useless (e.g., Kahneman and Knetsch, 1992; Diamond et al., 1993) to assertion that embedding can be eliminated by providing sufficient information in a survey (Carson and Mitchell, 1993). But it may be common that scope insensitivity can be diluted only if sufficient information in a survey is provided.

This paper presents a methodology not only to evaluate the economic value of improvement of hydrologic vulnerability using the CE but also to do a CBA of some feasible alternatives combining the derived values with the alternative evaluation index (AEI). And then we apply this method in the Anyangcheon watershed. This study follows the socialeconomic-engineering combined procedure shown in Fig. 1 in order to allow for broad stakeholder participation. This procedure consists of four parts which are to spatially identify the grades on hydrological vulnerability (part I), to evaluate the monetary values of improvements on hydrological vulnerability grades (part II), to derive an AEI to quantify the effectiveness of all alternatives (part III), and to combine the derived WTPs with the AEI and do the CBA of feasible alternatives (part IV)

To avoid scope insensitivity of CE, the present spatial hydrologic vulnerability developed in Lee and Chung (2007) 
and improved by Chung and Lee (2009b) is introduced into part I and used to support the respondents with the sufficient information of study watershed. Therefore, residents can respond with the correct and realistic WTPs of improvements on the present hydrological vulnerability grades in the application of a CE, since they can recognize and confirm the status in their place of residence. Furthermore this paper uses the alternative evaluation index (AEI) developed by Chung and Lee (2009a) to estimate the monetary values of alternatives by linearly combining AEI with WTPs.

\section{Choice experiment}

\subsection{Overview}

Methods for valuing the environment are classified into revealed preference (RP) methods and stated preference (SP) methods, and both methods have advantages and drawbacks. RP methods make use of the actual behavior of people, and examples of these methods include the household production model, travel cost demand model, and hedonic property value and hedonic wage models. SP methods draw their data from people's responses to hypothetical questions, and include CVM and CE. CVM questions ask directly about monetary value for environmental change, while choice experiments do not reveal monetary measures directly (Freeman III, 2003).

$\mathrm{CE}$ (or choice modeling) is often called choice-based conjoint analysis (conjoint logit model). Conjoint analysis is categorized into compositional and decompositional methods, and the latter are more widely used. Decompositional conjoint analysis is also categorized into full-profile-rating conjoint analysis, contingent ranking, choice experiments and pair-wise choice experiments (pair-wise-rating conjoint analysis). Recently, CE and pair-wise CE are frequently being used and responses to hypothetical questions in choice experiments are more likely to reflect actual behavior of consumers than those in the other types of conjoint analysis (Nakatani et al., 2007).

$\mathrm{CE}$ is becoming a popular means of environmental valuation (Bennett and Blamey, 2001; Hanley et al., 2001; Collins et al., 2005; Willis et al., 2005). CE encompasses a variety of multi-attribute preference elicitation techniques widely used by market researchers to evaluate potential new products and new markets for existing products (Garrod and Willis, 1997). CE is a suitable method for valuing environmental goods with multi-attributes (Baarsma, 2003). Recently, this approach was employed as an alternative to CVM and to complement other preferred methods such as the hedonic price model and travel cost method. In addition, the National Oceanic and Atmospheric Administration (NOAA) in the United States has included this technique in its recent rule-making governing natural-resource damage assessments for oil spills (Johnson and Desvousges, 1997).
CE has a number of advantages. Above all, it is easier than other valuation methods in estimating the value of each attribute that makes up an environmental good. This is useful because many policies are more concerned with changing attribute levels, rather than losing or gaining the environmental good as a whole (Hanley et al., 1998). It allows respondents to systematically evaluate trade-offs among multiple environmental and non-environmental attributes. This trade-off process may encourage respondent introspection and facilitate consistency checks on response patterns (Johnson and Desvousges, 1997). In addition, as it does not ask for the WTP of respondents, it reduces the number of protest responses, especially those involving tax increases or willingness to accept environmental degradation in return for payment. It also increases the amount of information obtained from each respondent, thus reducing the required sample, and hence reducing the costs of the survey (Yoo et al., 2008).

In this study, CE is used in order to estimate the economic value of environmental indicator improvement. In brief, a $\mathrm{CE}$ asks individuals to choose the most preferred alternative in each choice set. Each alternative consists of several attributes and several choice sets are presented to each individual (Carlsson and Martinsson, 2001). If one of the attributes has a monetary price, then it is possible to calculate the responses' marginal willingness-to-pays (MWTPs) for the other attributes on the basis of the responses.

\subsection{Design procedure}

The design procedure of CE consists of five stages. The first stage is selection of attributes. This is usually done through literature reviews, focus group discussions or direct questioning. Sometimes they may be self-evident because of the nature of the problem. A monetary cost should be one of the attributes, to allow the estimation of WTP. The second stage is assignment of levels. The attribute levels should be realistic and span the range over which we expect respondents to have preferences, and/or should be practically-achievable. The third stage is choice experimental design. Statistical design theory is used to combine the levels of the attributes into a number of alternative environmental scenarios or profiles to be presented to respondents. Complete factorial designs allow the estimation of the full effects of the attributes upon choices: that includes the effects of each of the individual attributes presented ("main effects") and the extent to which behavior is connected with variations in the combination of different attributes of offered ("interactions"). These designs often produce an impracticably large number of combinations to be evaluated. Fractional factorial designs are able to reduce the number of scenario combinations presented, with a concomitant loss in estimating power, i.e. some of all of the interactions will not be detected. The fourth stage is construction of choice sets. The profiles identified by the experimental design are then grouped into choice sets to be presented to respondents. Profiles can be presented 
individually, in pairs or in groups according to the technique being used. The fifth stage is measurement of preferences including choice of survey procedure and conduct of survey (Bateman et al., 2002).

\subsection{Random utility model}

The choice experiment approach was initially developed by Louviere and Hensher (1982) and Louviere and Woodworth (1983). Choice experiments share a common theoretical framework with dichotomous-choice contingent valuation in the Random Utility Model (McFadden, 1973), as well as a common basis of empirical analysis in limited dependent variable econometrics (Greene, 2002). According to this framework, the direct utility function for each respondent, $x$, can be decomposed into two parts: a deterministic element $(Z)$, which is typically specified as a linear index of the attributes $(X)$ of the different alternatives $(j)$ in the choice set, and a stochastic element $(e)$, which represents unobservable influences on individual choice. This is shown in Eq. (1):

$G_{x j}=Z_{x j}\left(X_{x j}\right)+e_{x j}=b X_{x j}+e_{x j}$.

Thus, the probability that any particular respondent prefers option $g$ in the choice set to any alternative option $h$ can be expressed as the probability that the utility associated with option $g$ exceeds that associated with all other options, as stated in Eq. (2):

$$
\begin{aligned}
& \operatorname{Pr}\left[\left(G_{x g}>G_{x h}\right) \forall h \neq g\right] \\
& \quad=\operatorname{Pr}\left[\left(V_{x g}-V_{x h}\right)>\left(e_{x h}-e_{x g}\right)\right] .
\end{aligned}
$$

In order to derive an explicit expression for this probability, it is necessary to know the distribution of the error terms $\left(e_{x j}\right)$. A typical assumption is that they are independently and identically distributed with an extreme-value (Weibull) distribution:

$$
\operatorname{Pr}\left(e_{x j} \leq t\right)=F(t)=\exp (-\exp (-t)) .
$$

The above distribution of the error term implies that the probability of any particular alternative $g$ being chosen as the most preferred can be expressed in terms of the logistic distribution (McFadden, 1973), stated in Eq. (4). This specification is known as the conditional logit model:

$$
\operatorname{Pr}\left(G_{x g}>G_{x h}, \quad \forall h \neq g\right)=\frac{\exp \left(\mu V_{x g}\right)}{\sum_{j} \exp \left(\mu V_{x j}\right)},
$$

where $\mu$ is the scale parameter that is inversely proportional to the standard deviation of the error distribution. This parameter cannot be separately identified and is therefore typically assumed to be one. An important implication of this specification is that selections from the choice set must obey the independence from the irrelevant alternatives (IIA) property, which states that the relative probabilities of two options being selected are unaffected by the introduction or removal of other alternatives. This property follows from the independence of the Weibull error terms across the different options contained in the choice set.

\section{Study watershed description}

The Anyangcheon watershed (AY) is selected in this study. Anyangcheon (stream) is the first tributary of the Han River in Korea. The study stream has a length of $32 \mathrm{~km}$. The watershed is bounded by the latitudes $37^{\circ} 18^{\prime} \mathrm{N}$ and $37^{\circ} 33^{\prime} \mathrm{N}$ and the longitudes $126^{\circ} 47^{\prime} \mathrm{E}$ and $127^{\circ} 04^{\prime} \mathrm{E}$.

The average annual precipitation from 1972 to 2001 is reported as $1325 \mathrm{~mm}$. $70 \%$ of the precipitation occurs during the monsoon months from June to September, and the rest (30\%) occurs from October to May. However, it has been reported that the average annual precipitation changed during the next five years (2002 2006). The average annual precipitation and occupancy of monsoon months increased up to $1468 \mathrm{~mm}$ and $74 \%$, respectively. That is, since the intensity of wet period becomes higher and the amount of rainfall in the remaining months decreased ( 392 to $385 \mathrm{~mm}$ ), flood control during the wet period and water security during the dry period have become increasingly difficult.

On the basis of the digital elevation model (DEM), stream network, and storm sewers, the study watershed is divided into 11 sub-watersheds (upstream: OJ, WG, DJ, SB; middlestream: HU, SA, SB1, SS; downstream: SH, MG, DR). The watershed area, in which approximately 388 million people reside, is $287 \mathrm{~km}^{2}$ (population density: 13527 persons per $\mathrm{km}^{2}$ ). Primary land cover types within the watershed (as of the year of 2000) comprise $43 \%$ of urban area, $40 \%$ of forest area, and $13 \%$ of agricultural areas.

\section{Economic evaluation of hydrologic vulnerability im- provement}

\subsection{Identification of hydrologic vulnerability (part I)}

Chung and Lee (2009b) presented the values and grades of PFD (potential flood damage), PSD, PWQD and WEI (watershed evaluation index) of all sub-watershed using PressureState-Response framework (OECD, 1993) and various multicriteria decision making (MCDM) techniques. This study introduces the values and grades of PSD and PWQD from the weight summation method. All criteria and their weights of Lee and Chung (2007) are used. The number of grade is five ("A" "E") and their characteristics are as follows: A $(0 \sim 0.3$, very sound); $\mathrm{B}(0.3 \sim 0.4$, quite sound); $\mathrm{C}(0.4 \sim 0.5$, Moderate); $\mathrm{D}(0.5 \sim 0.6$, quite poor); and $\mathrm{E}(0.6 \sim 1.0$, very poor).

From grades of PSD and PWQD and their locations, all the sub-watersheds can be divided into six regions as follows: Region I (WG, OJ); Region II (DJ, SB); Region III (HU); Region IV (SA, SS, SB); Region V (MG); Region VI (DR, $\mathrm{SH})$. Regions I and II are located in the upstream and "D" 
Table 1. Level and values of attributes.

\begin{tabular}{llcccccc}
\hline Attribute & Level & I & II & III & IV & V & VI \\
\hline PSD & Dangerous (5) & & & & & & Base \\
& Partially dangerous (4) & Base $^{\mathrm{a}}$ & Base & & Base & Base & B1 \\
& Moderate (3) & B1 $^{\text {b }}$ & B1 & & B1 & B1 & B2 \\
& Partially safe (2) & B2 & B2 & & B2 & B2 & \\
& Safe (1) & & & Base & & & \\
& Ideal (0) & & & B1 & & & \\
\hline PWQD & Dangerous (5) & & Base & & & Base & Base \\
& Partially dangerous (4) & & C1 & & & C1 & C1 \\
& Moderate (3) & Base & & C2 & Base & C2 & C2 \\
& Partially safe (2) & C1 & & & C1 & & \\
Safe (1) & C2 & & Base & C2 & & \\
& Ideal (0) & & & C1 & & & \\
\hline
\end{tabular}

${ }^{\mathrm{a}}$ Base means the present condition. ${ }^{\mathrm{b}} \mathrm{B} 1$ and $\mathrm{B} 2$ are the 1 st and 2 nd target grades of PSD and $\mathrm{C} 1$ and C2 of PWQD.

grade of PSD but have quite different water quality grades. Region I is "C" but II is "E". Regions III and IV are located in the middle-stream but have totally different vulnerability patterns. Region III is very good (both "A") but IV has "C" or "D" of PSD and "D" of PWQD. Regions V and VI are located in the downstream but have different vulnerability in PSD. Region V is "D" grade but VI "E".

\subsection{Economic valuation using choice experiment method}

\subsubsection{Selection of attributes and assignment of levels}

In the choice experiment method, the attributes should be selected based on the five following criteria. First, the attributes should be independent or nearly independent of one another (Kwak et al., 2001). Second, there should only be a small number of attributes, preferably not more than six, because trade-offs become difficult to understand and to show to respondents in a comprehensible form if there are too many attributes (Phelps and Shanteau, 1978). Third, attributes should be describable by combining simple explanations and visual instruments, such as photographs, charts, and pictures. Fourth, attributes should be scientifically meaningful and important facts should not be omitted. Fifth, attributes should have some meaning to people and relate to their reasons for having the WTP to avoid mental impact (Yoo et al., 2008).

In this study, PSD and PWQD are selected for the attributes of choice experiment. Their levels are divided into six grades on the basis of Sect. 4.1's grades "A" "E". The "AA" grade is added as a sixth grade to represent the ideal condition. Each has its own target grade, since every sub-watershed cannot be an "AA" grade. Since all subwatersheds are divided into six regions in the Sect. 4.1, six experimental designs are necessary in this study. The levels and values of the attributes for the six regions are shown in Table 1.

The amounts of additional tax payment per household are set at three levels: 2500, 5000, and 10000 won/household (1 US dollar corresponds to 1000 won as of May 2008). These amounts are determined on the basis of the acceptability of an annual payment per household. Although the amounts actually bear no relation to the costs of the projects, respondents are asked to assume that the additional tax will be imposed only for implementing the projects for prevention of streamflow depletion and water quality enhancement. A result of CVM (Kong et al., 2006) in the study watershed and some preliminary surveys are used to determine the range of public payment acceptability.

\subsubsection{Choice of experimental design and construction of choice sets}

A choice set must obey IIA property. This property states that the relative probabilities of two options being selected are unaffected by the introduction or removal of other choices. This property follows from the independence of the error terms across the different options contained in the choice set.

In designing a $\mathrm{CE}$, it is important to carefully define the attribute space (including attribute and range) such that the attribute space includes the portion relevant to the policy questions being asked. Furthermore, a $\mathrm{CE}$ involves the use of statistical design theory to construct choice sets that can yield coefficient estimates that are not confounded by other factors. This study used the orthogonal main effects design which is effective in terms of isolating the effects of individual attributes on the choice. The ability to "design in" this orthogonality is an important advantage over the revealed preference random utility models, where attributes in reality are often found to be highly correlated with one another (Hanley et al., 1998; Yoo et al., 2008). The orthogonal main effects 
design is implemented by using the SAS Macro PROC OPTEX procedure. SAS Macro PROC OPTEX usually optimizes designs based on the factors specified, levels of factors and model statements.

For most practical purposes, fractional factorial designs must be used. Fractional factorial designs are generated by selecting subsets of choice sets from the full factorial design. The two most common fractional factorial designs are the main effects only and main effects + two way interaction effects designs. In a main effects only design, a sub-set of the full factorial design is selected such that all the main effects (or linearly additive utility terms) are identifiable and completely orthogonal with each other. Employing a main effects only design drastically reduces the number of choice sets needed in an analysis.

Although employing main effects designs reduce the number of choice sets in a CE application, the resulting design may still be too large from a practical application standpoint. Kuhfeld et al. (1994) proposed a method of selecting options from the full factorial design by minimizing the D-efficiency criterion. With these types of designs, a minimum number of observations, denoted as $\mathrm{M}$, needed to identify the parameters of interest is selected, - i.e., a design with the minimum number of degrees of freedom (Kuhfeld, 2003).

Using a D-efficiency design, a number of profiles, in addition to "the status quo option" are selected from the number of possible combinations of attribute levels. The results are 2 Choice sets $\times 9$ Questions for Regions I, II, IV, V, and VI and 2 Choice sets $\times 6$ Questions or Region III. Each of the questions contains three choices, with two positive payments and the status quo choice. Six types of questionnaires are drawn up and 6 or 9 choice sets (conjoint questions) are included in each questionnaire.

\subsubsection{Model of this study}

The utility function of the model without covariates, with the exception of the error term $e_{x j}$, can be expressed as a linear function of an attribute vector $\left(S_{1}, S_{2}, Q_{1}, Q_{2}, T\right)=\left(\mathrm{PSD}_{1}\right.$, $\mathrm{PSD}_{2}, \mathrm{PWQD}_{1}, \mathrm{PWQD}_{2}$, Tax). It includes one alternativespecific constant (ASC), which represents a dummy for the respondent's choosing the status quo option in the choice set. ASC captures the utility of the choice that the attributes fail to capture (Adamowicz et al., 1994).

But, in order to explain the preference heterogeneity and the WTP variations among individuals, it is useful to use choice model specifications where some individual-specific variations are taken into account. The individual-specific variables include the residents' sex, age, number of family members, education, visit of stream, income, NGO registration, concerns about development and preservation, length of marriage and residence period.

Two versions of choice models with covariates have been suggested. First, Greene (2002) proposed multiplying demographic variables by dummy variables for each choice within a set. However, if residents need to answer multiple questions, it would be impractical to use this model because separate dummies would be required for each distinct option to the status quo option faced by each individual. Second, Gordon et al. (2001) presented the idea of making the individualspecific variables interact with ASC terms in the utility function. Since this is ideally suited for our data, we choose to make the nine individual-specific variables interact with ASC. This can be formulated through the following utility function:

$$
\begin{aligned}
V_{i j}= & \mathrm{ASC}_{j}+\beta_{1} S_{1, i j}+\beta_{2} S_{2, i j}+\beta_{3} Q_{1, i j}+\beta_{4} Q_{2, i j} \\
& +\beta_{5} T_{i j}+\sum_{s=1}^{9} \phi_{S} \mathrm{ASC}_{i} K_{s i}
\end{aligned}
$$

where $S_{1}, S_{2}, Q_{1}, Q_{2}$, and $T$ means element variables $\left(\mathrm{PSD}_{1}, \mathrm{PSD}_{2}, \mathrm{PWQD}_{1}, \mathrm{PWQD}_{2}\right.$, and Tax) of attribute vector, the $\beta \mathrm{s}$ are the parameters to be estimated for each attribute that influences the respondent's utility, $K_{s i}$ is the individual-specific variables and $\phi_{s}$ is the parameter to be estimated for the individual-specific variables multiplied by ASC.

If we are calculating the MWTP from the status quo level of each attribute and assume that all of the following MWTP can be found by totally differentiating Eq. (5) and omitting $i$ for brevity:

$\operatorname{MWTP}_{S_{1}}=-\left(\partial V / \partial S_{1}\right) /(\partial V / \partial T)=-\beta_{1} / \beta_{5}$,

$\operatorname{MWTP}_{S_{2}}=-\left(\partial V / \partial S_{2}\right) /(\partial V / \partial T)=-\beta_{2} / \beta_{5}$

$\operatorname{MWTP}_{Q_{1}}=-\left(\partial V / \partial Q_{1}\right) /(\partial V / \partial T)=-\beta_{3} / \beta_{5}$

$\operatorname{MWTP}_{Q_{2}}=-\left(\partial V / \partial Q_{2}\right) /(\partial V / \partial T)=-\beta_{4} / \beta_{5}$

The MWTPs of each attribute represent the marginal rate of substitution between the price and each attribute.

\subsubsection{Questionnaires and Survey}

Since all respondents are residents and stakeholders in the study watershed, the sufficient information transfer is very important. Therefore, the description of study watershed including some pictures, the purpose and backgrounds of survey, and the present conditions (grades of PSD and PWQD) of all sub-watersheds are shown before answering questions in the questionnaires. In addition, the statement is added that respondents don't have to pay the money they select and just answer the willingness-to-pay not to avoid the inactive response.

Since this study is the first study to use a CE for evaluating the environmental costs of hydrologic vulnerability in water resource planning, it is not clear whether the respondents had fully understood the trade-offs between price and the hydrologic attributes described in the questionnaire. Therefore, we conduct person-to-person interviews where we give detailed questions to respondents in order to obtain higher effective response rates. 


\begin{tabular}{|c|c|c|c|c|}
\hline \multicolumn{5}{|c|}{$\begin{array}{l}<\text { Q 1> For each set of options(include status-quo) presented, we would like you to select one } \\
\text { option which you would choose for the Region I ( }\end{array}$} \\
\hline \multirow{4}{*}{$\begin{array}{l}\begin{array}{l}\text { Status-quo } \\
\text { option (1) }\end{array} \\
\text { Option (2) } \\
\end{array}$} & \multirow{2}{*}{\begin{tabular}{|c|} 
Lose \\
Tax for the \\
Anyangcheon \\
watershed \\
improvements
\end{tabular}} & \multicolumn{3}{|c|}{ Take } \\
\hline & & $\begin{array}{l}\text { Flood damage } \\
\text { possibilities }\end{array}$ & Instreamflow & Water quality \\
\hline & 0 won & Dangerous (5) & Moderate (3) & Dangerous (5) \\
\hline & 10,000 won & Dangerous (5) & Partially safe (2) & Moderate (3) \\
\hline Option (3) & 2,500 won & Partially safe (2) & Safe (1) & $\begin{array}{l}\text { Partially dangerous } \\
\text { (4) }\end{array}$ \\
\hline \multicolumn{5}{|c|}{$\begin{array}{l}<Q 2>\text { For each set of options(include status-quo) presented, we would like you to select one } \\
\text { option which you would choose for the Region I ( ) }\end{array}$} \\
\hline & Lose & \multicolumn{3}{|c|}{ Take } \\
\hline & $\begin{array}{l}\text { Tax for the } \\
\text { Anyangcheon } \\
\text { watershed } \\
\text { improvements }\end{array}$ & $\begin{array}{l}\text { Flood damage } \\
\text { possibilities }\end{array}$ & Instreamflow & Water quality \\
\hline $\begin{array}{l}\text { Status-quo } \\
\text { option (1) }\end{array}$ & 0 won & Dangerous (5) & Moderate (3) & Dangerous (5) \\
\hline Option (2) & 5,000 won & Dangerous (5) & Safe (1) & $\begin{array}{c}\text { Partially } \\
\text { Dangerous (4) }\end{array}$ \\
\hline Option (3) & 10,000 won & Moderate (3) & Partially safe (2) & Dangerous (5) \\
\hline
\end{tabular}

Fig. 2. Example of choice set.

About one hundred respondents of each questionnaire are sampled at random from the official resident registration of the city, in which all residents of the city are recorded. If one of the questions is irrationally answered, the questionnaire is regarded as an ineffective response. Irrational answers can be represented as follows: If the answer to Q1 is (2) in Fig. 2, the answer to Q2 should also be (2), since the responder has a willingness to pay for the prevention of instreamflow depletion and water quality enhancement. But if the answer to Q2 is (3), the questionnaire is assumed to be useless since we cannot trust the understanding and consistency of the respondent.

\subsubsection{WTP estimates of each attribute}

The choice data are analyzed using SAS 9.1. The estimation results of the model with covariates are presented in Table 2. Some of the coefficients of covariates are not significant at the $10 \%$ level. However, most coefficients are statistically significant at that level. Most of the individual-specific variables for the six regions are not consistent because residents' inclination to stream is quite different for their regions. The socio-demographic and attitudinal variables have different impacts on the respondents of different regions.

In Region I, there are notable declines in the coefficients on sex, age, family, education, concerns, resident years, frequency of visit, income, ngo, and marriage. The coefficients for family and education are significant at the $1 \%$ and $10 \%$ levels, and age, income, and concern are significant at the $5 \%$ level. In Region II, there are notable declines in the coefficients on age and year and increases in sex, family, education, visits, income, ngo, concerns, and marriage. The coefficients for family and income are significant at the $10 \%$ level, and age and visits are significant at the $1 \%$ level. In Region III, there are notable declines in the coefficients on age, visits, ngo, and years and increases in sex, family, education, income, concerns, and marriage. The coefficients for education and marriage are significant at the $1 \%$ level and family, visits, ngo, age and income are significant at the 5\% level. In Region IV, there are notable declines in the coefficients on age, concerns, marriage, and year and increases in sex, family, education, visits, income, and ngo. The coefficients for age and income are significant at the $1 \%$ level and visits, marriage, and years are significant at the 5\% level. In Region $\mathrm{V}$, there are notable declines in the coefficients on family, education, concerns, and years and increases in sex, age, visits, income, ngo, and marriage. The coefficient for family is significant at the $1 \%$ level and age and education are significant at the 5\% level. In Region VI, there are declines in the coefficients on age, income, concerns, and marriage and increases in sex, family, education, visits, ngo, and years. The coefficients for age and concern are significant at the $1 \%$ level, education is significant at the $5 \%$ level, and family, visits, and marriage were significant at the $10 \%$ level. Overall, these models show an improvement, with a pseudo$R^{2}>0.2$ and a pseudo- $R^{2}$ approaching 0.4 , which is usually considered an exceptionally good fit (Hensher and Johnson, 1981).

The MWTP of respondents for obtaining one unit increase from the less preferred level of each attribute can be calculated by using Eq. (6). The results of MWTP estimates of the model with no covariates are shown in Table 3. For example, the MWTPs for water quality enhancement in Region VI are 598.4 won for level 1 up and 4569.7 won for level 2 up. These results present the graded WTP based on 
Table 2. Estimation results of the model with covariates.

\begin{tabular}{|c|c|c|c|c|c|c|c|c|c|c|}
\hline \multicolumn{2}{|l|}{ Variable } & \multicolumn{3}{|c|}{ I } & \multicolumn{3}{|c|}{ II } & \multicolumn{3}{|c|}{ III } \\
\hline \multirow{2}{*}{$\begin{array}{l}\text { Flood damage mitiga- } \\
\text { tion }\end{array}$} & 1 up & 0.0198 & $(0.18)$ & & 0.1159 & $(0.37)$ & & 0.1522 & (1.05) & \\
\hline & 2 up & & & & 0.1512 & $(1.22)$ & & & & \\
\hline \multirow{2}{*}{$\begin{array}{l}\text { Prevention of in- } \\
\text { streamflow depletion }\end{array}$} & 1 up & 0.4694 & $(2.50)$ & $\mathrm{b}$ & 0.1321 & (1.33) & & 0.0398 & $(0.23)$ & \\
\hline & 2 up & 0.9578 & $(5.20)$ & $\mathrm{c}$ & 0.2052 & $(2.17)$ & $\mathrm{b}$ & & & \\
\hline \multirow{2}{*}{$\begin{array}{l}\text { Water quality en- } \\
\text { hancement }\end{array}$} & 1 up & 0.5620 & (5.23) & $\mathrm{c}$ & 0.4597 & (1.33) & & 0.2465 & (1.45) & \\
\hline & 2 up & & & & 0.6802 & $(1.96)$ & a & & & a \\
\hline \multicolumn{2}{|l|}{ Financial support(P) } & -0.000095 & $(-4.61)$ & $\mathrm{c}$ & -0.000791 & $(-4.56)$ & $\mathrm{c}$ & -0.000163 & $(-4.89)$ & $\mathrm{c}$ \\
\hline \multicolumn{2}{|l|}{ ASC } & 4.9992 & $(3.53)$ & $\mathrm{c}$ & -1.6695 & $(-2.78)$ & $\mathrm{c}$ & -4.6946 & $(-2.35)$ & $\mathrm{b}$ \\
\hline \multicolumn{2}{|l|}{ ASC*sex } & -0.0448 & $(-0.15)$ & & 0.5222 & $(0.86)$ & & 0.0383 & $(0.09)$ & \\
\hline \multicolumn{2}{|l|}{ ASC*age } & -0.0433 & $(-2.22)$ & $\mathrm{b}$ & -0.0496 & $(2.87)$ & $\mathrm{c}$ & -0.0566 & $(-1.93)$ & a \\
\hline \multicolumn{2}{|l|}{ ASC*family } & -0.1898 & $(-4.49)$ & c & 0.1511 & $(1.81)$ & a & 0.5641 & $(2.38)$ & $\mathrm{b}$ \\
\hline \multicolumn{2}{|l|}{ ASC $*$ edu } & -0.1297 & $(-1.85)$ & $\mathrm{a}$ & 0.2087 & $(0.82)$ & & 0.3121 & (3.59) & $\mathrm{c}$ \\
\hline \multicolumn{2}{|l|}{ ASC*visit } & 0.0038 & $(1.55)$ & & 0.006193 & $(6.71)$ & $\mathrm{c}$ & -0.002745 & $(-2.16)$ & $\mathrm{b}$ \\
\hline \multicolumn{2}{|l|}{ ASC*income } & 0.0033 & $(2.52)$ & $\mathrm{b}$ & 0.001753 & $(1.87)$ & $\mathrm{a}$ & 0.003472 & (1.66) & a \\
\hline \multicolumn{2}{|l|}{ ASC*ngo } & 1.6336 & (1.17) & & 0.7874 & $(0.08)$ & & -1.6395 & $(-2.53)$ & $\mathrm{b}$ \\
\hline \multicolumn{2}{|l|}{ ASC $*$ concern } & -0.8832 & $(-2.27)$ & $\mathrm{b}$ & 0.006161 & $(0.65)$ & & 0.7866 & (1.59) & \\
\hline \multicolumn{2}{|l|}{ ASC*marriage } & 0.6027 & $(1.29)$ & & 0.8311 & $(1.05)$ & & 2.7384 & (2.85) & c \\
\hline \multicolumn{2}{|l|}{ ASC $*$ year } & -0.0188 & $(-0.85)$ & & -0.0256 & $(0.84)$ & & -0.005381 & $(-0.20)$ & \\
\hline \multicolumn{2}{|l|}{ Number of samples } & & 02 & & & 504 & & & 38 & \\
\hline Log-likelihood & & -5 & 8.78 & & & 375.12 & & -2 & 1.45 & \\
\hline $2 *\left(\log \mathrm{L}-\log \mathrm{L}_{0}\right)$ & & & 4.9 & & & 91.56 & & & .89 & \\
\hline Pseudo- $R^{2}$ & & & 51 & & & 0.38 & & & 50 & \\
\hline df & & & 6 & & & 18 & & & 5 & \\
\hline Variable & & & $\mathrm{V}$ & & & $\mathrm{V}$ & & & I & \\
\hline Flood damage mitiga- & 1 up & 0.0853 & $(0.47)$ & & 0.0198 & $(0.18)$ & & 0.2567 & $(1.34)$ & \\
\hline & 2 up & & & & & & & 0.8933 & (4.08) & $\mathrm{c}$ \\
\hline Prevention of in- & 1 up & 1.3647 & $(5.74)$ & c & 0.2181 & $(0.80)$ & & 0.2130 & $(1.01)$ & \\
\hline & 2 up & & & & 0.692 & $(2.51)$ & $\mathrm{b}$ & 0.4264 & $(2.03)$ & $\mathrm{b}$ \\
\hline Water quality en- & 1 up & 0.2065 & $(0.77)$ & & 0.5459 & $(1.78)$ & a & 0.0730 & $(0.30)$ & \\
\hline & 2 up & & & & 0.8083 & $(2.63)$ & $\mathrm{c}$ & 0.5575 & (2.33) & $\mathrm{b}$ \\
\hline Financial support(P) & & -0.000249 & $(-5.70)$ & $\mathrm{c}$ & -0.000106 & $(0.91)$ & & -0.000122 & $(-4.76)$ & $\mathrm{c}$ \\
\hline ASC & & -0.4170 & $(-0.24)$ & & 1.73 & $(-3.27)$ & c & 0.6778 & $(0.56)$ & \\
\hline ASC*sex & & 0.9671 & $(1.51)$ & & 0.52 & $(0.87)$ & & 0.0377 & $(0.14)$ & \\
\hline ASC*age & & -0.007079 & $(-3.50)$ & $\mathrm{c}$ & 0.2199 & $(2.41)$ & $\mathrm{b}$ & -0.0574 & $(-3.07)$ & $\mathrm{c}$ \\
\hline ASC*family & & 0.00425 & $(0.12)$ & & -0.5918 & $(-3.12)$ & c & 0.1617 & (1.77) & a \\
\hline ASC*edu & & 0.004905 & $(0.06)$ & & -0.2609 & $(-2.51)$ & $\mathrm{b}$ & 0.1370 & $(2.45)$ & $\mathrm{b}$ \\
\hline ASC*visit & & 0.00898 & $(2.20)$ & $\mathrm{b}$ & 0.002188 & $(1.45)$ & & 0.0065 & (1.86) & a \\
\hline ASC*income & & 0.005878 & $(2.78)$ & $\mathrm{c}$ & 0.002102 & $(1.00)$ & & -0.0004 & $(-0.38)$ & \\
\hline ASC*ngo & & 1.9168 & $(1.58)$ & & 1.1737 & $(0.97)$ & & 0.3738 & $(0.81)$ & \\
\hline ASC $*$ concern & & -0.3241 & $(-0.68)$ & & -0.3866 & $(-0.90)$ & & -0.9358 & $(-3.32)$ & $\mathrm{c}$ \\
\hline ASC*marriage & & -0.8671 & $(-2.11)$ & $\mathrm{b}$ & 1.2925 & $(1.00)$ & & -0.6489 & $(-1.81)$ & a \\
\hline ASC*year & & -0.065 & $(-2.39)$ & $\mathrm{b}$ & -0.0329 & $(-1.21)$ & & 0.0019 & $(0.10)$ & \\
\hline Number of samples & & 288 & & & 368 & & & 648 & & \\
\hline Log-likelihood & & -231.45 & & & -303.27 & & & -556.94 & & \\
\hline $2 *\left(\log \mathrm{L}-\log \mathrm{L}_{0}\right)$ & & 169.89 & & & 202.03 & & & 309.91 & & \\
\hline Pseudo- $R^{2}$ & & 0.50 & & & 0.48 & & & 0.43 & & \\
\hline df & & 15 & & & 17 & & & 18 & & \\
\hline
\end{tabular}

Notes: ${ }^{\mathrm{a}},{ }^{\mathrm{b}}$, and ${ }^{\mathrm{c}}$ indicate statistical significance at the $10 \%, 5 \%$ and $1 \%$ levels, respectively. 
Table 3. Estimates of implicit prices and total WTPs of six regions.

\begin{tabular}{|c|c|c|c|c|c|}
\hline Region & Attribute & $\begin{array}{c}\text { Present } \\
\text { Level }\end{array}$ & $\begin{array}{l}\text { Target } \\
\text { Level }\end{array}$ & $\begin{array}{c}\text { Implicit Prices } \\
\text { (won/month-household) }\end{array}$ & $\begin{array}{l}\text { Total WTP } \\
\text { (Korea won) }\end{array}$ \\
\hline \multirow{4}{*}{ I } & \multirow{2}{*}{ PSD } & \multirow[b]{2}{*}{4} & 3 & 4941.1 & 56703729 \\
\hline & & & 2 & 10082.1 & 115701496 \\
\hline & \multirow{2}{*}{ PWQD } & \multirow[b]{2}{*}{3} & 2 & 2356.2 & 27039591 \\
\hline & & & 1 & 5915.8 & 67889320 \\
\hline \multirow{4}{*}{ II } & \multirow{2}{*}{ PSD } & \multirow{2}{*}{4} & 3 & 1670.0 & 123025220 \\
\hline & & & 2 & 2594.2 & 191108998 \\
\hline & \multirow{2}{*}{ PWQD } & \multirow{2}{*}{5} & 4 & 5811.6 & 428127767 \\
\hline & & & 3 & 8599.2 & 633484117 \\
\hline \multirow{2}{*}{ III } & PSD & 1 & 0 & 244.2 & 25803165 \\
\hline & PWQD & 1 & 0 & 1512.3 & 159795770 \\
\hline \multirow{4}{*}{ IV } & \multirow{2}{*}{ PSD } & \multirow{2}{*}{4} & 3 & 2115.6 & 92463911 \\
\hline & & & 2 & 5480.7 & 239538174 \\
\hline & \multirow{2}{*}{ PWQD } & \multirow{2}{*}{3} & 2 & 829.3 & 36245189 \\
\hline & & & 1 & 4616.8 & 201780765 \\
\hline \multirow{4}{*}{ V } & \multirow{2}{*}{ PSD } & \multirow{2}{*}{4} & 3 & 2057.5 & 329951162 \\
\hline & & & 2 & 6528.3 & 1046911383 \\
\hline & \multirow{2}{*}{ PWQD } & \multirow[b]{2}{*}{5} & 4 & 5150.0 & 825880186 \\
\hline & & & 3 & 7625.5 & 1222863954 \\
\hline \multirow{4}{*}{ VI } & \multirow{2}{*}{ PSD } & \multirow{2}{*}{5} & 4 & 1745.9 & 581653391 \\
\hline & & & 3 & 3495.1 & 1164406190 \\
\hline & \multirow{2}{*}{ PWQD } & \multirow[b]{2}{*}{5} & 4 & 598.4 & 199358293 \\
\hline & & & 3 & 4569.7 & 1522413369 \\
\hline
\end{tabular}

the present conditions. In general the WTPs for water quality enhancement are larger than those for prevention of streamflow depletion except Regions I and IV. The WTPs of downstream watershed (Regions V and VI) are high, but upstream (Regions I and II) and middle-stream watershed (Regions III and IV) low. People in the Region I have the largest WTP for environmental improvement but residents in the Region III showing both "A" grades have the smallest WTPs.

The monthly WTPs for all the households in the six regions can be calculated by multiplying the average household's monthly WTP by the number of households for each of the six regions, respectively. Since there are 2.95 persons/household according to the Korea National Statistical Office, the total WTPs for the six regions can be calculated by the multiplying the WTP by the total number of households. The results are shown in the last column of Table 3 . The total WTP of Region VI is the largest because of large population. These values can be efficiently used for a option selection or budget appropriation.

\section{Cost benefit analysis}

\subsection{Calculation of AEI (part III)}

The AEI may be assumed to be linear combination with evaluation values of water quantity and quality. Therefore the AEI, $f\left(a_{i}\right)$ can be derived as follows.

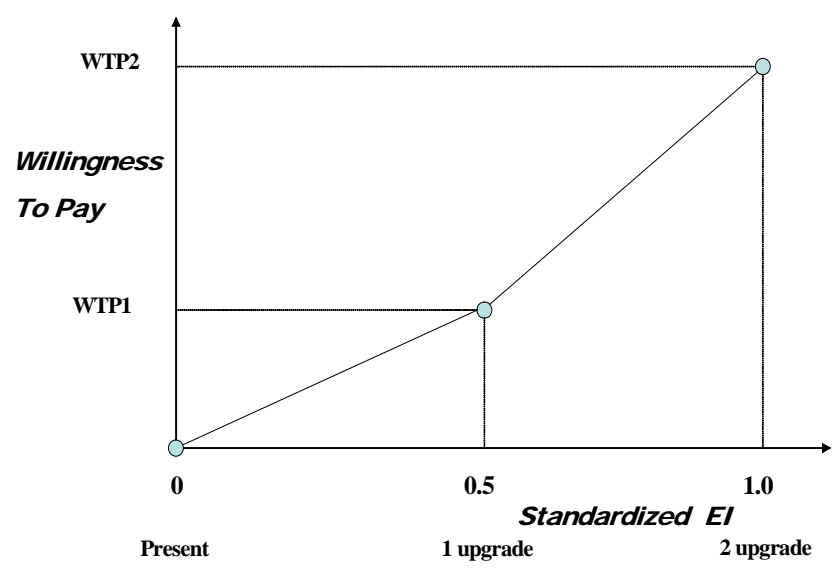

Fig. 3. Concept of continuous WTP estimation.

$f\left(a_{i}\right)=\alpha_{1} f_{1}\left(a_{i}\right)+\alpha_{2} f_{2}\left(a_{i}\right)$

where $a_{i}$ means the $i^{t h}$ feasible alternative, $f_{1}\left(a_{i}\right)$, and $f_{2}\left(a_{i}\right)$ are evaluation values of water quantity and quality and $\alpha_{1}$ and $\alpha_{2}\left(\alpha_{1}+\alpha_{2}=1\right)$ are the relative importance (weights) of water quantity and quality. $f_{1}\left(a_{i}\right)$, and $f_{2}\left(a_{i}\right)$ can be derived to consider the sustainability of the Driver-PressureState-Impact-Response (DPSIR) framework (European Environment Agency, 1999) which is an improved PSR model.

Chung and Lee (2009a) developed all feasible alternatives of the study watershed through the discussion with 
Table 4. Estimation of feasible alternatives benefit.

\begin{tabular}{|c|c|c|c|c|c|c|c|}
\hline \multirow[t]{2}{*}{$\begin{array}{l}\text { Name of } \\
\text { Alternative }\end{array}$} & \multicolumn{2}{|c|}{$\begin{array}{c}\text { Alternative } \\
\text { Evaluation Index (AEI) }\end{array}$} & \multicolumn{2}{|c|}{ Standardized AEI } & \multirow[t]{2}{*}{ WTP (won/year) } & \multirow[t]{2}{*}{$\begin{array}{r}\text { Estimated number } \\
\text { of household }\end{array}$} & \multirow[t]{2}{*}{$\begin{array}{r}\text { Benefit } \\
\text { (1000 won/year) }\end{array}$} \\
\hline & Quantity & Quality & Quantity & Quality & & & \\
\hline $\mathrm{R} 4$ & 0.537 & 0.493 & 0.13 & 0.27 & 3296.0 & 3430 & 11305 \\
\hline $\mathrm{S} 1$ & 0.549 & 0.676 & 0.18 & 0.88 & 8531.4 & 28790 & 246617 \\
\hline $\mathrm{S} 2$ & 0.527 & 0.663 & 0.09 & 0.84 & 8237.5 & 44878 & 369680 \\
\hline $\mathrm{S} 3$ & 0.504 & 0.572 & 0.00 & 0.53 & 1056.6 & 16936 & 17894 \\
\hline S4 & 0.604 & 0.711 & 0.40 & 1.00 & 5966.4 & 9241 & 580179 \\
\hline S5 & 0.662 & 0.67 & 0.63 & 0.86 & 5677.2 & 87767 & 498274 \\
\hline U2 & 0.664 & 0.415 & 0.64 & 0.00 & 2235.7 & 333154 & 744824 \\
\hline $\mathrm{S} 4+\mathrm{U} 3$ & 0.612 & 0.608 & 0.43 & 0.65 & 6078.2 & 97241 & 591044 \\
\hline S5+U4 & 0.712 & 0.658 & 0.83 & 0.82 & 6054.9 & 87767 & 531422 \\
\hline W1 & 0.754 & 0.415 & 1.00 & 0.00 & 3495.1 & 333154 & 1164406 \\
\hline
\end{tabular}

Table 5. Net benefits and BC ratios of all feasible alternatives.

\begin{tabular}{cccc}
\hline $\begin{array}{c}\text { Name of } \\
\text { alternative }\end{array}$ & $\begin{array}{c}\text { Period } \\
\text { (years) }\end{array}$ & $\begin{array}{c}\text { Net Benefit } \\
\text { (1000 won) }\end{array}$ & BC ratio \\
\hline R4 & 25 & 25766 & 1.18 \\
S1 & 100 & -10421993 & 0.33 \\
S2 & 100 & -17569230 & 0.30 \\
S3 & 100 & -7624735 & 0.05 \\
S4 & 100 & -28018277 & 0.30 \\
S5 & 100 & -33179149 & 0.24 \\
U2 & 25 & 8717984 & 4.40 \\
S4+U3 & 100 & -28834151 & 0.30 \\
S5+U4 & 100 & -33530475 & 0.25 \\
W1 & 25 & 4443519 & 1.34 \\
\hline
\end{tabular}

residents, local governmental officials and environmental engineers and then calculated their AEIs. This study screens the top ten alternatives and derived their AEIs using the weighted summation method.

\subsection{Economic valuation of all alternatives (part IV)}

Economic values of hydrological vulnerability improvement and the AEI can be integrated to evaluate the monetary effectiveness of all feasible alternatives. The derived WTPs are discrete, but the continuous WTPs are necessary because the exact effectiveness of alternatives is also continuous. Therefore this study develops the following equations to derive the continuous benefit combining the WTPs with the AEIs. These concepts are shown in Fig. 3.

$$
\begin{aligned}
B(i)= & \left(B_{1}(i)+B_{2}(i)\right) \times P H_{i} \\
B_{1}(i) & =\mathrm{WTP}_{1, i} \times 2 \times f_{1, i}^{\prime} \quad 0 \leq f_{1, i}^{\prime} \leq 0.5 \\
& =\mathrm{WTP}_{1, i}+2 \times W T P 2_{1, i} \times\left(f_{1, i}-0.5\right) \\
& 0.5<f_{1, i}^{\prime} \leq 1.0
\end{aligned}
$$

$$
\begin{aligned}
B_{2}(i) & =W T P 1_{2, i} \times 2 \times f_{2, i}^{\prime} \quad 0 \leq f_{2, i}^{\prime} \leq 0.5 \\
& =W T P 1_{2, i}+2 \times W T P 2_{2, i} \times\left(f_{2, i}-0.5\right) \\
& 0.5<f_{2, i}^{\prime} \leq 1.0
\end{aligned}
$$

where $B(i)$ is the total benefit of the alternative $i ; B_{1}(i)$, and $B_{2}(i)$ the benefits per household of alternative $i$ to water quantity and quality, respectively; $f_{1, i}^{\prime}\left(=\frac{f_{1, i}}{\max f_{1, i}}\right)$ and $f_{2, i}^{\prime}\left(=\frac{f_{2, i}}{\max f_{2, i}}\right)$ the standardized values of $f_{1, i}$ and $f_{2, i}$; WTP $1_{1, i}$ and WTP2 $2_{1, i}$ two-step WTPs for water quantity improvement; WTP1 $1_{2, i}$ and WTP2 $2, i$ two-step WTPs for water quality enhancement; $\mathrm{PH}_{i}$ the number of household of the watershed where alternative $i$ is applicable.

The benefits of ten feasible alternatives of Sect. 5.1 are calculated using Eqs. (8), (9) and (10) as shown in Table 4. The net benefit is necessary to determine the outstanding alternatives since the high benefit alternative usually requires high cost. The results of net benefit and $\mathrm{BC}$ ratio estimation are shown in Table 5, with interest rate 5\%, endurance period and maintenance cost. As a result, U2, W1 and R4 can be proposed as the final candidates to decision makers since they are turn out to be both economical and effective from this new procedure. That is, this study shows not that these three alternatives are so perfect to be performed as soon as possible, but that these can become just feasible candidates for the consideration of decision makers.

\section{Conclusion}

This study proposes the social-economic-engineering combined framework including four parts. The first and second parts are the combination of a choice experiment and indicators of sustainable development to evaluate the economic value of hydrologic vulnerability improvement. The indicators are PSD and PWQD which show the hydrologic vulnerability in water resource planning. All the components of PSD and PWQD are selected by PSR framework, and 
calculated by weighted summation method, a type of MCDM techniques. These indices can not only give site-specific information to the respondents of a survey to avoid scope sensitivity in the choice experiment, but also support the standard to divide the study watershed into similar sub-regions. Therefore, residents can respond with a realistic WTP for the correct application of the CE, since they can recognize and confirm the present condition of their place of residence. In addition, after dividing into sub-regions on the basis of hydrologic vulnerability and location, each WTP is estimated to consider the spatial characteristics. A single WTP is not realistic, since the regions have different conditions. Therefore, this combination of weighted summation method and a choice experiment can make an improvement in the precise estimation of site-specific WTPs. The third and fourth parts are the combination of the WTPs and the AEIs to estimate the exact economic valuation of all feasible alternatives is the most original in this study. The CE just shows the economic values of several alternatives and improvement of environmental attributes. But this approach can provide the economic values of all alternatives from the values of environmental attributes improvement and the AEI. Finally, we carry out these four steps in the highly-urbanized watershed of Korea.

This study develops an appropriate method in which stakeholder opinions or preferences are quantitatively reflected on weights of indicators and monetary values of environmental improvements. This systematic screening procedure will provide decision makers with the flexibility to obtain stakeholders' consensus for water resources planning.

Some choice experiment applications already exist, but this is the first study to develop a combination of hydrologic vulnerability grading and a choice experiment supplied with exact and concise information. Lastly, this research provides a useful social-economic-engineering combined framework for incorporating such quantitative information into the evaluation of various policies with regard to water resource planning and management.

Acknowledgements. This research was supported by a grant (1-7-3) from Sustainable Water Resources Research Center of $21^{\text {st }}$ Century Frontier Research Program of Ministry of Science and Technology (90\%) through Engineering Research Institute of Seoul National University and Safe and sustainable Infrastructure Research (10\%).

Edited by: L. A. Swatuk

\section{References}

Abrahams, N. A., Hubble, B. J., and Jordan, J. L.: Joint production and averting expenditure measures of willingness to pay: Do water expenditures really measure avoidance costs?, Am. J. Agric. Econom., 82(2), 427-437, 2000.

Adamowicz, W., Louviere, J., and Williams, M.: Combining revealed and stated preference methods for valuing environmental amenities, J. Environ. Econ. Manage., 26, 271-292, 1994.
Baarsma, B. E.: The valuation of the Ijmeer reserve using conjoint analysis, Environ. Resour. Econ., 25, 343-356, 2003.

Bateman, I., Carson, R., Day, B., Hanemann, M., Hanley, N., Hett, T., Jones-Lee, M., Loomes, G., Mourato, S., Ozdemiroglu, E., Pearce, D. W., Sugden, R., and Swanson, J.: Economic Valuation with Stated Preference Techniques: A Manual, Edward Elgar, Cheltenham, 2002.

Bennett, J. and Blamey, R.: The Choice Modelling Approach to Non Market Valuation, Cheltenham UK and Northampton, MA, USA: Edward Elgar, 2001.

Carlsson, F. and Martinsson, P.: Do hypothetical and actual marginal willingness to pay differ in choice experiments? Application to the valuation of the environment, J. Environ. Econ. Manage., 41, 179-192, 2001.

Carson, R. T. and Mitchell, R. C.: The issue of scope in contingent valuation studies, Am. J. Agric. Econ., 75, 1263-1267, 1993.

Christofides, A., Efstratiadis, A., Koutsoyiannis, D., Sargentis, G.F., and Hadjibiros, K.: Resolving conflicting objectives in the management of the Plastiras Lake: can we quantify beauty?, Hydrol. Earth Syst. Sci., 9, 507-515, 2005, http://www.hydrol-earth-syst-sci.net/9/507/2005/.

Chung, E. S. and Lee, K. S.: Prioritization of water management for sustainability using hydrologic simulation model and multicriteria decision making techniques, J. Environ. Manage., 90(3), 1502-1511, 2009a.

Chung, E. S. and Lee, K. S.: Identification of spatial ranking of hydrological vulnerability using multicriteria decision making techniques: Case study of Korea, Water Resour. Manage., published online, 2009b.

Collins, A., Rosenberger, R., and Fletcher, J.: The economic value of stream restoration, Water Resour. Res., 41, W02017, doi:10.1029/2004WR003353, 2005.

Cupps, R. A.: Emerging problems of citizen participation, Pub. Admin. Rev., 37, 478-487, 1997.

Diamond, P. and Hausman, J. A.: Contingent valuation: Is some number better than no number?, J. Econ. Perspec., 8, 45-64, 1994.

European Environment Agency: Environmental Indicators: Typology and Overview, Copenhagen, Denmark, 1999.

Freeman III, A. M.: The Measurement of Environmental and Resource Values: Theory and Methods, second ed. Resources for the Future, Washington D.C., 23-26, 2003.

Garrod, G. D. and Willis, K. G.: The non-use benefits of enhancing forest biodiversity: A contingent ranking study, Ecol. Econ., 21, 45-61, 1997.

Gordon, J., Chapman, R., and Blamey, R.: Assessing the Options for Canberra Water Supply: An Application of Choice Modeling in the Choice Modeling Approach to Environmental Valuation, Edward Elgar, 2001.

Greene, W. H.: Econometric Analysis, fourth ed. Prentice-Hall, London, 2002.

Hanley, N., Mourato, A., and Wright, R.: Choice modeling approaches: A superior alternative for environmental evaluation?, J. Econ. Survey, 15(3), 435-462, 2001.

Hanley, N., Wright, R. E., and Adamowicz, W.: Using choice experiments to value the environment, Environ. Resour. Econ., 11, 413-428, 1998.

Hanley, N., Wright, R. E., and Alvarez-Farizo, B.: Estimating the economic value of improvements in river ecology using choice 
experiments: An application to the water framework directive, J. Environ. Manage., 78, 183-193, 2006.

Harrison, G. W.: Valuing public goods with the contingent valuation method: A critique of Kahneman and Knetsch, J. Environ. Econ. Manage., 23, 248-257, 1992.

Hensher, D. and Johnson, L.: Applied Discrete Choice Modeling, Wiley, New York, 1981.

Howe, C. W. and Smith, M. G.: The value of water supply reliability in urban water systems, J. Envir. Econom. Manage., 26, 19-30, 1994.

Johnson, F. R. and Desvousges, W. H.: Estimating stated preferences with rated-pair data: Environmental, health, and employment effects of energy programs, J. Environ. Econ. Manage., 34, 79-99, 1997.

Kahneman, D. and Knetsch, J. L.: Valuing public goods: the purchase of moral satisfaction, J. Environ. Econ. Manage., 22, 5770, 1992.

Kong, K. S., Chung, E. S., Yoo, J. C., and Lee, K. S.: Estimating attributes value of alternatives applied for rehabilitation of hydrologic cycle of the Anyangcheon watershed, J. Korea Water Resour. Assoc., 39, 1031-1042, 2006.

Kuhfeld, W. F., Tobias, R. D., and Garratt, M.: Efficient experimental design with marketing research applications, J. Market. Res., 31, 545-557, 1994.

Kuhfeld, W. F.: Marketing Research Methods in SAS: Experimental Design, Choice, Conjoint, and Graphical Techniques, SAS Inst., Cary, N. C., 2003.

Kwak, S. J., Yoo, S. H., and Kim, T. Y.: A constructive approach to air quality valuation in Korea, Ecol. Econ., 38, 327-344, 2001.

Lee, K. S. and Chung, E. S.: Development of integrated watershed management schemes for intensively urbanized region in Korea, J. HydroEnviron. Res., 1(2), 95-109, 2007.

Louviere, J. and Hensher, D.: On the design and analysis of simulated choice or allocation experiments in travel choice modeling, Transport. Res. Rec., 890, 11-17, 1982.

Louviere, J. and Woodworth, G.: Design and analysis of simulated consumer choice or allocation experiments: An approach based on aggregate data, J. Marketing Res., 20, 350-367, 1983.
McFadden, D.: Conditional logit analysis of qualitative choice behavior, in: Frontiers in Econometrics, edited by: Zarembka, P., Academic Press, New York, 1973.

Nakatani, J., Aramaki, T., and Hanaki, K.: Applying choice experiments to valuing the different types of environmental issues in Japan, J. Environ. Manage., 84, 362-376, 2007.

OECD: OECD core set of indicators for environmental performance reviews, OECD Environment Monographs 83, OECD, Paris, 1993.

Phelps, R. H. and Shanteau, J.: Livestock judges: How much information can an expert use?, Organization Behavior and Human Performance, 21, 209-219, 1978.

Raadgever, G. T., Mostert, E., and van de Giesen, N. C.: Identification of stakeholder perspectives on future flood management in the Rhine basin using Q methodology, Hydrol. Earth Syst. Sci., 12, 1097-1109, 2008, http://www.hydrol-earth-syst-sci.net/12/1097/2008/.

Rosener, J.: Making bureaucracy responsive: A study of impacts of citizen participation and staff recommendation on regulatory decision making, Pub. Admin. Rev., 42, 339-345, 1982.

Schulze, W. D., McClelland, G. H., Lazo, J. K., and Rowe, R. D.: Embedding and calibration in measuring non-use values, Resour. Ener. Econ., 20, 163-178, 1998.

Thomas, J. C.: Public involvement in public management: adapting and testing a borrowed theory, Pub. Admin. Rev., 50, 435-445, 1990.

van den Belt, M.: Mediated Modeling: A System Dynamics Approach to Environmental Consensus Building, Island Press, 2004.

Willis, K., Scarpa, R., and Acutt, M.: Assessing water company customer preferences and willingness to pay for service improvements: A stated choice analysis, Water Resour. Res., 41, W02019, doi:10.1029/2004WR003277, 2005.

Yoo, S. H., Kwak, S. J., and Lee, J. S.: Using a choice experiment to measure the environmental costs of air pollution impacts in Seoul, J. Environ. Manage., 86, 308-318, 2008. 